\title{
A COMPARISON OF EFFICACY OF INTRADERMAL TRANEXAMIC ACID WITH TOPICAL 20\% AZELAIC ACID IN THE TREATMENT OF MELASMA
}

\author{
Sayyida Komal, Asher Ahmed Mashhood*, Muhammad Farooq, Nida Qayyum \\ Combined Military Hospital Peshawar/National Institute of Medical Sciences (NUMS) Pakistan, *Combined Military Hospital/National Institute of Medical \\ Sciences (NUMS) Rawalpindi Pakistan
}

\begin{abstract}
Objective: To compare the efficacy of Intradermal Tranexamic acid and topical 20\% Azelaic acid cream in the treatment of melasma.

Study Design: Comparative prospective study.

Place and Duration of Study: Dermatology department, Combined Military Hospital Peshawar, from Sep 2018 to Mar 2019.

Methodology: A total of 116 female patients, at the outpatient department of dermatology at Combined Military Hospital Peshawar, were randomly assigned into two groups; group A (intradermal tranexamic acid) and group B (topical azelaic acid) by lottery method. Patients in group A received intradermal injection, while the participants of group B received topical azelaic acid only, fortnightly for 6 weeks. Melasma area severity index score was calculated for each patient in both groups at the start and at the end of the treatment.

Results: The mean Melasma area severity index score in group A (intradermal tranexamic acid) before and at 6 weeks of treatment was $7.10 \pm 2.94$ and $5.27 \pm 2.44$, respectively. The mean Melasma area severity index score in group B (topical azelaic acid) before and at 6 weeks of treatment was $7.56 \pm 2.57$ and $5.76 \pm 2.89$, respectively. Efficacy of intradermal tranexamic acid, as poor response, good response and excellent response was $27.6 \%, 41.4 \%$ and $31 \%$ respectively. While, efficacy of topical azelaic acid group as poor response, good response and excellent response was $62.1 \%, 20.7 \%$ and $17.2 \%$ respectively. The difference was statistically significant, $(p=0.001)$.

Conclusion: It can be concluded that intradermal tranexamic acid is more effective as compared to topical $20 \%$ azelaic acid in the treatment of melasma.
\end{abstract}

Keywords: Azelaic acid, Intradermal injections, Melasma, Topical therapy, Tranexamic acid.

\footnotetext{
This is an Open Access article distributed under the terms of the Creative Commons Attribution License (http://creativecommons.org/licenses/by/4.0), which permits unrestricted use, distribution, and reproduction in any medium, provided the original work is properly cited.
}

\section{INTRODUCTION}

Melasma is a chronic acquired hyperpigmentation of the skin characterized by light to dark macules or patches that more or less symmetrically involve the sun exposed areas; most commonly the face, neck and occasionally the forearms. It occurs mostly in women of reproductive age but can also occur in post-menopausal women and men $(10 \%)^{1}$. The prevalence of melasma during pregnancy is variable in different countries. In Pakistan, melasma was identified in $46 \%$ pregnant women².

The precise etiology of melasma is unknown but many factors are known to cause it, including an exposure to ultraviolet radiation, pregnancy, contraceptive pills, hormone replacement therapy, cosmetics and phototoxic drugs ${ }^{3}$. Among skin phenotypes, Fitzpatrick skin type IV is the most prone to develop melasma followed by Fitzpatrick skin type $\mathrm{V}^{4}$.

Melasma distorts the appearance of an individual and tends to create an immense emotional and psychological distress for the patient. Women in our society

Correspondence: Dr Asher Ahmed Mashhood, Department of Skin, Combined Military Hospital Rawalpindi Pakistan

Received: 16 Jun 2020; revised received: 10 Aug 2020; accepted: 17 Aug 2020 are likely to have a stigma due to their appearance and they feel social isolation due to their disease. It ultimately severely affects the quality of life ${ }^{5}$.

Different treatment options have been tried in melasma including topical depigmenting agents (e.g. hydroquinone, alpha arbutin, mequinol, azelaic acid, magnesium ascorbyl phosphate, tretinoin and topical corticosteroids), chemical peels (e.g. salicylic acid, glycolic acid, kojic acid, lactic acid), dermabrasion and laser therapies (including Pico laser, Q-switched laser and intense pulsed light). They have been used over the time with different results ${ }^{1,7}$. Despite this variety of options, treatment is usually unsatisfactory with high recurrence rates. Therefore, there is a dire need to find an effective, swift and sustainable treatment option.

Tranexamic acid, a traditional hemostatic drug, was accidentally discovered to be effective in melasma, when in 1979 Nijo in Japan found its effectiveness while treating chronic urticaria. It acts by inhibiting plasminogen activator. Plasminogen is present in keratinocytes. Under the influence of plasminogen activator, it is converted into plasmin. Plasmin stimulates the release of arachidonic acid and its metabolites among which the most significant is Prostaglandin E2. Prost- 
aglandin E2 stimulates melanogenesis. Hence by inhibiting plasminogen activator, Tranexamic acid inhibits the melanogenesis ${ }^{1}$.

Several studies have found that Tranexamic acid reduces pigmentation in melasma. It has been used topically, orally and intradermal 1,2,6,7.

This study compares the efficacy of intradermal Tranexamic acid and $20 \%$ topical azelaic acid, which is a known, well tolerated and safe treatment ${ }^{8}$ for melasma. This comparison has been done in order to establish intradermal Tranexamic acid as an effective treatment option for melasma. No such comparative study with topical azelaic acid has been done previously.

\section{METHODOLOGY}

This comparative prospective study was carried out in the department of Dermatology, Combined Military Hospital Peshawar, from September 2018 to March 2019. Sample size was calculated to be 116 by using the hypothesis tests for two population proportions (one sided test). Intradermal Tranexamic acid in group 1 (P1= 40\%), topical Azelaic acid in group 2 (P2= $63 \%)^{8,9}$. Taking level of significance $5 \%$ and Power of test $80 \%$, using the following formula

$$
\begin{gathered}
n=\{\mathrm{Z} 1-\alpha \sqrt{2 \mathrm{P}(1-\mathrm{P})}+\mathrm{Z} 1-\beta \sqrt{\mathrm{P} 1(1-\mathrm{P} 1)} \\
+\mathrm{P} 2(1-\mathrm{P} 2)\}^{2} \div(\mathrm{P} 1-\mathrm{P} 2)^{2}
\end{gathered}
$$

A total of 116 female patients, aged between 25-45 years, with melasma were enrolled in the study using consecutive, non-probability sampling technique. Study was started after taking approval from the ethics review committee of the institute. Consent form was signed by each patient. Patients who were suffering from some major medical illness were excluded from the study (screening was done by doing base line investigations including ECG, chest $x$-ray, random blood sugar, blood complete picture, liver and renal profile). Patients who had used any anti-melasma treatment in the past 3 months as well as those who were pregnant were also excluded from the study.

For random allocation of patients in two equal groups, lottery method was used. All participants of group A received intradermal TXA injection, $20 \mathrm{mg}$ diluted in $0.8 \mathrm{ml}$ of Normal saline fortnightly. The total dose of TXA per visit depended upon the total area affected by melasma. Hence every patient received from 1 to $3 \mathrm{ml}$ of the solution (20-60mg of TXA) per visit. The injections were given on day 1 and then after every two weeks till they received a total of three treatments. While the participants of group B received once daily application of $20 \%$ Azelaic acid only. Both groups used broad spectrum sunblock of sun protecting factor (SPF) 60. The duration of treatment in both groups was 6 weeks, with follow up after every 2 weeks. Those patients who still failed to show up on follow up despite reminders were subtracted from the total in the final results.

MASI score was measured at the start and then at 6 weeks, in every patient of both groups. Statistical analysis was done using Statistical Program for Social Sciences (SPSS-22). Means and standard deviation were calculated for age, duration of illness, duration of sun exposure and MASI score (darkness of pigment, homogeneity of pigment, surface area involved).

Qualitative variables like efficacy (poor, good and excellent response; implying a $25 \%, 25-74 \%$ and \& gt; $75 \%$ reduction in MASI score from baseline respectively), marital status, use of contraceptives/drugs and sun exposure were presented in the form of frequencies and percentages. Chi-square test was applied to compare the effectiveness of the two treatment modalities.

A $p$-value $\leq 0.05(5 \%)$ was considered as significant. For better elaboration of results, tables were used. Efficacy was stratified among age, duration of illness, marital status, use of contraceptives/drugs and sun exposure to see effect modification using chi square test and keeping $p$-value $\leq 0.05$ as significant.

\section{RESULTS}

Total 116 patients were enrolled in the study. The patients were distributed into two groups, group A (Intradermal TXA), 58 (50\%) and group B, (TAA) 58 $(50 \%)$. The mean age, duration of illness and duration of sun exposure of the ITA patients (group A) was $34.15 \pm 3.64$ years, $3.96 \pm 1.93$ years and $3.36 \pm 1.08$ days, respectively. The mean MASI score in ITA patients before and after 6 weeks of treatment was $7.10 \pm$ 2.94 and $5.27 \pm 2.44$, respectively. All the demographic details of group A is given in table-I. There were 54 $(93.1 \%)$ patients married and $4(6.9 \%)$ un-married in ITA group. Twenty three (39.7\%) patients were used contraceptives/drugs in ITA group. History of daily sun exposure at least four hours or more for $\leq 6$ months was $40(69 \%)$ in ITA group.

While, the mean age, duration of illness and duration of sun exposure of the TAA patients (group B) was $37.61 \pm 3.97$ years, $4.53 \pm 2.32$ years and $3.89 \pm$ 1.12 days, respectively. The mean MASI score in TAA patients before and after 6 weeks of treatment was 7.56 \pm 2.57 and $5.76 \pm 2.89$, respectively. All the demograp- 
hic details of group B is given in table-I. There were 46 $(79.3 \%)$ patients married and $12(20.7 \%)$ un-married in TAA group. Twenty seven (46.6\%) patients were used contraceptives/drugs in TAA group. History of daily that combination therapy with intradermal tranexamic acid $(100 \mathrm{mg} / \mathrm{ml})$ and $4 \%$ topical hydroquinone, given monthly was more effective than conventional $4 \%$ hydroquinone monotherapy after 3 months in the

Table-I: Demographic characteristics of both groups.

\begin{tabular}{l|c|c} 
Variable & $\begin{array}{c}\text { Intradermal } \\
\text { Tranexamic acid (n=58) }\end{array}$ & $\begin{array}{c}\text { Topical azelaic acid } \\
(\mathbf{n = 5 8 )}\end{array}$ \\
\hline Age (years) & $34.15 \pm 3.64$ & $37.61 \pm 3.97$ \\
\hline Duration of illness (years) & $3.96 \pm 1.93$ & $4.53 \pm 2.32$ \\
\hline Duration of sun exposure (days) & $3.36 \pm 1.08$ & $3.89 \pm 1.12$ \\
\hline Melasma area severity index score (before treatment) & $7.10 \pm 2.94$ & $7.56 \pm 2.57$ \\
\hline Melasma area severity index score (after treatment) & $5.27 \pm 2.44$ & $5.76 \pm 2.89$ \\
\hline
\end{tabular}

sun exposure at least four hours or more for $\leq 6$ months was $54(93.1 \%)$ in TAA group.

Efficacy of ITA group as poor response, good response and excellent response was 16 (27.6\%), 24 $(41.4 \%)$ and $18(31 \%)$, respectively. While, efficacy of TAA group as poor response, good response and excellent response was $36(62.1 \%), 12(20.7 \%)$ and 10 $(17.2 \%)$, respectively. The difference was statistically significant, $(p=0.001)$ (table-II).

\section{DISCUSSION}

Melasma is a very common cosmetic disorder, especially among Asians. Despite the many different treatment options available, it remains to be one of the most refractory conditions to treat with a high recurrence rate. Tranexamic acid is a relatively new treatment for melasma that is being used topically, orally and intradermal. However, there are inadequate stu-

Table-II: Efficacy in both groups.

\begin{tabular}{|c|c|c|c|}
\hline Variable & $\begin{array}{l}\text { Intradermal } \\
\text { tranexamic } \\
\text { acid }(n=58)\end{array}$ & $\begin{array}{c}\text { Topical } \\
\text { azelaic acid } \\
(\mathbf{n}=58)\end{array}$ & $\begin{array}{c}p- \\
\text { value }\end{array}$ \\
\hline Poor response & $16(27.6 \%)$ & $36(62.1 \%)$ & \multirow{3}{*}{0.001} \\
\hline Good response & $24(41.4 \%)$ & $12(20.7 \%)$ & \\
\hline Excellent response & $18(31 \%)$ & $10(17.2 \%)$ & \\
\hline
\end{tabular}

dies that have evaluated localized tranexamic acid intradermal injection as an effective and safe method ${ }^{10}$.

A split face controlled trial study by Nasrin Saki at Shiraz University of medical sciences, Iran in 2018, has shown that monthly intradermal Tranexamic acid $(100 \mathrm{mg} / \mathrm{ml})$ can be more effective than $2 \%$ hydroquin one after 4 weeks of treatment but after 20 weeks, the overall improvement was not different with both treatments, suggesting a shorter onset of action with intradermal tranexamic acid ${ }^{10}$. In 2018, a study done by Zohreh et al, at the Skin Research Center, Shahid Beheshti University of Medical Sciences, Iran, showed treatment of melasma ${ }^{11}$.

A randomized controlled trial study done by Patil at Maharashtra, India in 2019 showed that intradermal Tranexamic acid $(4 \mathrm{mg} / \mathrm{ml})$ was more effective than topical triple combination (hydroquinone $2 \%$, tretinoin $0.025 \%$, fluocinolone acetonide $0.01 \%$ ) followed by $3 \%$ topical Tranexamic acid, after monthly treatment sessions for 6 months ${ }^{12}$.

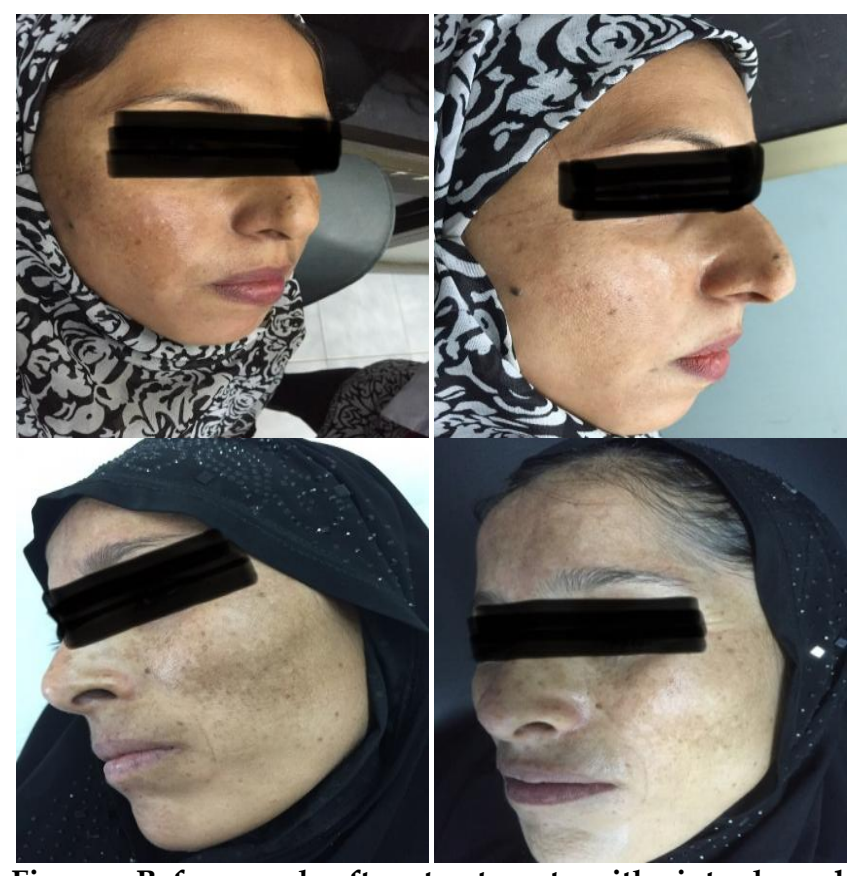

Figure: Before and after treatment with intradermal tranexamic acid.

In 2015, Elfar NN, in a randomized controlled trial on intradermal Tranexamic acid $(4 \mathrm{mg} / \mathrm{ml})$ showed significant reduction in MASI core at week 24, but it was less effective than silymarin cream and $50 \%$ glycolic acid peeling7.

A comparative study done between Intradermal Tranexamic acid and oral Tranexamic acid by Shetty 
at J Institute of Medical Sciences, Karnataka, India, in 2018 showed higher efficacy with intradermal Tranexamic acid $(4 \mathrm{mg} / \mathrm{ml})$, given 3 weekly for 12 weeks as compared to oral $250 \mathrm{mg}$ Tranexamic acid was given twice a day for 12 weeks in the other group. Furthermore, the benefit of intradermal Tranexamic acid over oral Tranexamic acid is that it won't cause any systemic effects like headaches, menstrual irregularity, nausea and back pain ${ }^{13}$.

With more evidence showing the role of interaction between keratinocytes and melanocytes in melanogenesis, through the plasminogen activation system, it is justifiable to add Tranexamic acid as an adjuvant in the treatment of melasma. It can make a known treatment more effective and can make a recurrence less likely ${ }^{14}$.

Our study compared the efficacy of intradermal Tranexamic acid with $20 \%$ topical azelaic acid, with which it has not been compared previously in any study.

Azelaic acid is a known treatment for melasma that inhibits tyrosinase and decreases hyper-pigmentation. It is well tolerated and has no known drug interactions. Much improvement was seen in a study done by $\mathrm{N}$ J Lowe on dark skinned individuals (Fitzpatrick skin types IV-VI) treated with $20 \%$ Azelaic acid for 24 weeks $^{15}$. A study done by Farshi at Tehran, Iran in 2011, in a randomized controlled trial on two groups of women with melasma revealed that $20 \%$ Azelaic acid cream may be more effective as compared to $4 \%$ hydroquinone after 2 months of treatment ${ }^{16-18}$. However, there was no follow up data after 2 months of treatment.

This study shows that intradermal Tranexamic acid is more effective than $20 \%$ topical azelaic acid when treating melasma. However, a limitation of our study was a short treatment period that might not detect the long term side effects. Future studies should keep an eye on the dose of intradermal Tranexamic acid and the duration of treatment. We suggest conducting studies comparing the efficacy of intradermal Tranexamic acid with different concentrations and for longer duration of time.

\section{CONCLUSION}

It can be concluded based on the results of our study that intradermal tranexamic acid is more effective as compared to topical $20 \%$ azelaic acid in the treatment of Melasma. In terms of MASI score, intra- dermal tranexamic acid is significantly effective as compared to topical azelaic acid.

\section{CONFLICT OF INTEREST}

This study has no conflict of interest to be declared by any author.

\section{REFERENCES}

1. Poojary S, Minni K. Tranexamic Acid in Melasma: A Review. J Pigment Disord 2015; 2(12): 228-32.

2. Handel AC, Miot LD, Miot HA. Melasma: a clinical and epidemiological review. An Bras Dermatol 2014; 89(5): 771-82.

3. Lee AY. An updated review of melasma pathogenesis. Dermatol Sin 2014; 32(4): 233-39.

4. Amin N, Mashhood AA, Bilal A. Association of epidermal melasma with skin phenotypes and other contributing factors. J Pak Assoc Dermatol 2016; 26(3): 188-92.

5. Ikino JK, Nunes DH, da Silva VPM, Sens MM, Frode TS. Melasma and assessment of the quality of life in brazilian women. An Bras Dermatol 2015; 90(2): 196-200.

6. Taraz M, Niknam S, Ehsani AH. Tranexamic acid in treatment of melasma: a comprehensive review of clinical studies. Dermatol Ther 2017; 30(3): 65-73.

7. Elfar NN, El-Maghraby GM. Efficacy of intradermal injection of tranexamic acid, topical silymarin and glycolic acid peeling in the treatment of melasma: a comparative study. J Clin Exp Dermatol 2015; 6(3): 280.

8. Emad M, Moezzi J, Dastgheib L. Therapeutic efficacy of a cream based azelaic acid $20 \%$ versus hydroquinone $4 \%$ in patients with melasma. Iran J Dermatol 2013; 16(1): 13-16.

9. Budamakuntla L, Loganathan E, Suresh DH, Shanmugam S. A randomised, open-label, comparative study of tranexamic acid microinjections and tranexamic acid with microneedling in patients with melasma. J Cutan Aesthet Surg 2013; 6(3): 139-43.

10. Saki N, Darayesh M, Heiran A. Comparing the efficacy of topical hydroquinone $2 \%$ versus intradermal tranexamic acid microinjections in treating melasma: a split-face controlled trial. J Dermatol Treat 2018; 29(4): 405-10.

11. Tehranchinia Z, Saghi B, Rahimi H. Evaluation of therapeutic efficacy and safety of tranexamic acid local infiltration in combination with topical $4 \%$ hydroquinone cream compared to topical $4 \%$ hydroquinone cream alone in patients with melasma: a splitface study. Dermatol Res Prac 2018; (2): 1-5.

12. Patil SS, Deshmukh AR. Comparative study of efficacy of intradermal tranexamic acid versus topical tranexamic acid versus triple combination in melasma. Pigment Int 2019; 6: 84-95.

13. Vinma H, ShettyM. Comparative study of localised intradermal microinjection of tranexamic acid and oral tranexamic acid for the treatment of melasma. Int J Res Dermatol 2018; 4(3): 363-67.

14. Tse TW, Hui E. Tranexamic acid: an important adjuvant in the treatment of melasma. J Cosmetic Dermatol 2013; 12(1): 57-66.

15. Lowe NJ, Rizk D, Grimes P, Billips M, Pincus S, et al. Azelaic acid $20 \%$ cream in the treatment of facial hyperpigmentation in darker-skinned patients. Clin Ther 1998; 20(5): 945-59.

16. Farshi S. Comparative study of therapeutic effects of $20 \%$ azelaic acid and hydroquinone $4 \%$ cream in the treatment of melasma. J Cosmet Dermatol 2011; 10(4): 282-87.

17. Maibach HI. Pharmionics in dermatology. A Review of Topical Medication Adherence. Am J Clin Dermatol 2006; 7(1): 231-36.

18. Ebner F, Heller A, Rippke F. Topical Use of Dexpanthenol in Skin Disorders. Am J Clin Dermatol 2002; 3 : 427-33. 